\title{
Positive Emotions Boost Enthusiastic Responsiveness to Capitalization Attempts. Dissecting Self-Report, Physiology, and Behavior
}

\author{
Lukasz D. Kaczmarek ${ }^{1}$ (D) - Todd B. Kashdan² $\cdot$ Maciej Behnke ${ }^{1} \cdot$ Martyna Dziekan ${ }^{1}$. \\ Ewelina Matuła ${ }^{1} \cdot$ Michał Kosakowski $^{1}$ - Jolanta Enko ${ }^{3}$. Przemysław Guzik ${ }^{4}$
}

Accepted: 30 March 2021 / Published online: 13 April 2021

(C) The Author(s) 2021

\begin{abstract}
When individuals communicate enthusiasm for good events in their partners' lives, they contribute to a high-quality relationship; a phenomenon termed interpersonal capitalization. However, little is known when individuals are more ready to react enthusiastically to the partner's success. To address this gap, we examined whether positive and negative emotions boost or inhibit enthusiastic responses to partner's capitalization attempts (RCA). Participants ( $N=224$ individuals) responded to their partner's success. Before each capitalization attempt (operationalized as responses following the news that their partner won money in a game), we used video clips to elicit positive (primarily amusement) or negative (primarily anger) or neutral emotions in the responder. We recorded emotional valence, smiling intensity, verbal RCA, and physiological reactivity. We found indirect (but not direct) effects such that eliciting positive emotions boosted and negative emotions inhibited enthusiastic RCA (smiling intensity and enthusiastic verbal RCA). These effects were relatively small and mediated by emotional valence and smiling intensity but not physiological reactivity. The results offer novel evidence that positive emotions fuel the capitalization process.
\end{abstract}

This project was funded by the National Science Centre, Poland (UMO-2014/15/B/HS6/02418) awarded to LDK (principal investigator), TBK (key investigator), and PG (key investigator).

Preparation of this article was supported by doctoral scholarships from National Science Centre in Poland (UMO-2019/32/T/HS6/00039) and Adam Mickiewicz University Foundation to MB.

Lukasz D. Kaczmarek

lkacz1@gmail.com

1 Department of Psychology and Cognitive Science, Adam Mickiewicz University, 89

Szamarzewskiego Street, 60-658 Poznań, Poland

2 George Mason University, Fairfax, USA

3 SWPS University of Social Sciences and Humanities in Poznan, Poznań, Poland

4 Poznan University of Medical Science, Poznań, Poland 


\section{Introduction}

When good things happen, individuals communicate their positive events to others; a phenomenon termed capitalization attempts for positive events (Gable et al., 2004; Langston, 1994). The most desirable response to a capitalization attempt occurs when partners (responders) showcase enthusiasm for the information disclosed as opposed to being passive, withdrawn, or directly undermining the retelling of past positive events (Gable et al., 2006; Woods et al., 2015). Although the effects of enthusiastic responding are promising, little is known what affective states motivate responders to be enthusiastic in response to other's good events (c.f. Peters, Reis, \& Gable, 2018a, 2018b, for a review).

We aimed to uncover whether positive emotions' elicitation fosters and negative emotions inhibit enthusiastic responding to accomplishments in romantic relationships. We aimed to account for three interrelated but relatively independent levels of the emotional response: experience (whether individuals feel pleasure or displeasure in the situation), physiological responses (how individuals mobilize their energy needed for emotion expression and action), and behaviors (how individuals express their feelings and act upon emotions) (Mauss et al., 2005). Going beyond self-report is necessary for explaining which systems need to be engaged in individuals to achieve greater readiness for enthusiastic responding. Moreover, using physiological methods allows researchers to observe behavior without the interpretative difficulties inherent with self-reports (Enko et al., 2020).

\section{The Importance of Being Enthusiastic to the Communicated Good News}

There are four ways to react when another person shares positive self-relevant information: active-constructive, passive-constructive, passive-destructive, and active-destructive feedback (Gable et al., 2004; Pagani et al., 2013). Active-constructive feedback is defined as enthusiastic support and is the healthiest way to respond to a capitalization attempt. In contrast, the other three types of feedback-passive-constructive (understated support), passive-destructive (ignoring the event or the partner), and active-destructive (demeaning the event) — are linked to negative outcomes (Gable et al., 2004, 2006; Woods et al., 2015).

Individuals receiving more enthusiastic feedback report greater life satisfaction (Gable et al., 2012), happiness (Demir \& Davidson, 2013; Gable et al., 2004), positive affect (Gable et al., 2004; Monfort et al., 2014; Lambert et al., 2013), less anxiety (Gable et al., 2012) and negative affect (Gable et al., 2004; Monfort et al., 2014). Moreover, individuals feel more understood, grateful, and cared for by their partners after receiving enthusiastic responses following positive self-disclosures (Gable et al., 2006; Woods et al., 2015). Furthermore, enthusiastic responding within couples facilitates relationship quality (Donato et al., 2014; Gable et al., 2006), intimacy (Otto et al., 2015), and trust (Gable et al., 2004). Positive outcomes of enthusiastic responding occur for spontaneous (Gable et al., 2006) as well as trained responses (Conoley et al., 2015; Woods et al., 2015), for the capitalizer (Woods et al., 2015) and the responder (Schueller, 2012), in clinical (Otto et al., 2015) and non-clinical groups (Lambert et al., 2013).

Despite the benefits of sending and receiving enthusiastic feedback, the capitalization literature focused on understanding the responder's perspective is limited. What we do know is that the willingness to provide enthusiastic feedback might result from individuals 
enjoying making others feel good because it also increases their own positive emotions (Reis et al., 2017; Zaki \& Williams, 2013). Moreover, responders might be more likely to respond with enthusiasm when they believe that increasing their partner's happiness facilitates their performance (Netzer et al., 2015). Finally, responders might respond with enthusiasm because individuals obtain a self-esteem boost by including successful close partners into their self-concept and "basking in reflected glory" (Peters et al., 2018a, b). In contrast, enthusiastic capitalization feedback is inhibited when partners possess personality traits related to negative emotionality such as social anxiety (Kashdan et al., 2013), insecure attachment (Shallcross et al., 2011), or experience depressive symptoms (Horn et al., 2017).

What we do not know about responders is whether there are situational effects that enhance or dampen enthusiasm towards partner accomplishments. Manipulating situational factors might affect responder behavior (Kaczmarek et al., 2021). Establishing directional links is essential for evidence-based practice, such as positive psychological interventions (or happiness interventions) targeting the capitalization process in everyday life (Lambert et al., 2013; Schueller, 2012) or in education settings (Seligman et al., 2009). Building upon prior work, we tested whether responders are more likely to provide more enthusiasm upon experiencing positive emotions or dampen enthusiasm upon experiencing negative emotions such as anger.

\section{Capitalization Support and Emotions}

We propose that preceding affective states partially determine when some individuals are more likely to respond with enthusiasm to partner capitalization attempts. We build this expectation upon theories proposing that a person's current emotions influence motivation to act in a certain way (DeWall et al., 2016; Fredrickson, 2001; Frijda, 1986; Izard \& Ackerman, 2000). For instance, positive emotions motivate individuals to be prosocial (Aknin et al., 2017). Resources for enthusiastic responses may be readily accessible to partners experiencing positive emotions before their partner's capitalization attempt. In contrast, experiencing negative emotions can hinder an enthusiastic response because transitioning from negative to positive emotional states is likely to be particularly burdensome compared to switching from neutral to positive emotional states (Cacioppo \& Berntson, 1994; Russell \& Carroll, 1999).

\section{A Multivariate Approach to Capitalization}

The majority of literature on capitalization assesses emotions using self-reports (e.g., Demir \& Davidson, 2013; Ilies et al., 2015). Only three capitalization studies used physiological indicators (Gouin et al., 2019; Monfort et al., 2014; Peters, Reis, \& Jamieson, $2018 \mathrm{a}, \mathrm{b})$. Subjective, physiological, and behavioral responses are only moderately interrelated during a response to an affective stimulus (Mauss \& Robinson, 2009; Mauss et al., 2005). This suggests that self-reports are insufficient to explain physiology and, above all, behavior in the capitalization process. For instance, a recent study indicated the benefits of accounting for cardiovascular responses in positive psychological interventions because the cardiovascular response indicates the threat was predictive of lower behavioral engagement in the intervention (Enko et al. 2020). 
Studies on capitalization might also benefit from a more fine-grained investigation into the emotional reaction of responders. Responding with enthusiasm requires mobilization of physiological activity (Shiota et al., 2011). Moreover, physiological responses offer several methodological advantages, such as continuous, relatively unobtrusive measurement. Finally, there are benefits of interpreting self-reports, physiology, and behavior together. For instance, similar behavioral responses might be interpreted as trust or risk-taking depending on whether the same behavior (e.g., entrusting money to other individuals) is accompanied by parasympathetic (tend-and-befriend) or sympathetic (flight-or-flight) activation (Drażzowski et al., 2017). Consequently, if physiological responses were not engaged and did not mediate the relationship between the provision of affective stimuli and responding to partner's success, we might interpret that the process is guided by reflective rather than an impulsive system which dominates when homeostasis is disturbed (Strack \& Deutsch, 2004). Increasing the output of capitalization studies reaching beyond self-report and behavior is likely to provide a nuanced understanding of what states are necessary for responders to supply relational enthusiasm.

We focused on physiological processes that reflect a balance between sympathetic vs. parasympathetic arousal. Higher sympathetic activation (or parasympathetic withdrawal) is indicated by increases in heart rate, systolic blood pressure, diastolic blood pressure, and skin conductance that indicates activation of sweat glands (Blascovich et al., 2011). Moreover, a recent study on capitalization focused on cardiovascular markers of challenge/ threat (Peters, Reis, \& Jamieson, 2018a, 2018b). Decreased cardiac output (the amount of blood pumped by the heart in a minute) and increased total peripheral resistance (resistance of blood flow due to narrowing of arteries in response to cortisol) are characteristic for threatened individuals with little control over the situation. The oppositive hemodynamic response (increased cardiac output and decrease total peripheral resistance) is characteristic for challenged individuals who feel in control of the situation and successfully perform the tasks (Behnke \& Kaczmarek, 2018). The study on capitalization and cardiovascular challenge/threat response found that cardiovascular threat responses correlated with less enthusiastic responses to capitalization attempts (Peters, Reis, \& Jamieson, 2018a, b).

In our research, we accounted for smiling intensity in two forms of emotion expression: spontaneous (reflecting what individuals are experiencing, e.g., pleasure) or posed (when individuals deliberately form and present facial displays to exert social influence) (Crivelli \& Fridlund, 2018). Facial expression was already used in a previous study on capitalization and revealed greater sensitivity to types of capitalization feedback relative to physiological measures (skin conductance) (Monfort et al., 2014). The previous study used a facial expression to observe the effects of capitalization responses in the capitalizer and the responder. We used smiling intensity to observe whether affective stimuli produced meaningful responses (increasing spontaneous smiling for positive and suppressing smiling for negative clips), and whether responders smile to convey enthusiasm non-verbally to the capitalizer while providing feedback (increasing or suppressing posed smiles dependent on elicited emotions).

\section{Present Study}

We aimed to examine how elicited positive and negative emotions influence responding to a partner's success (i.e., RCA). We developed an experimental procedure for romantic couples in which partners watched film clips that elicited positive or negative emotions 
and subsequently responded to their partner's capitalization attempts. We accounted for smiling intensity and verbal response as indicators of enthusiastic RCA. We also measured emotions (emotional valence, smiling intensity, and physiological reactivity) to account for mediators. By testing mediation (or indirect effects), we examined whether emotions explain why individuals watching affective clips provided enthusiastic responses to their partner's capitalization attempts or diminished their enthusiasm for partner's accomplishments. Moreover, mediators' inclusion often increases power relative to testing total effects only (Kenny \& Judd, 2014; O’Rourke \& MacKinnon, 2015). Thus, testing mediation decreases the odds of type II error when less pronounced effects are studied. Building upon prior studies (Aknin et al., 2017; Fredrickson et al., 2008; Lambert et al., 2013), we expected that elicited positive emotions would facilitate enthusiastic responding whereas negative emotion would inhibit enthusiastic responding. We expected that the effects of elicited emotions on responding to partners' success would be mediated by physiological responses with lower sympathetic activation / higher parasympathetic activation (i.e., lower blood pressure reactivity) predictive of stronger enthusiasm and more smiling intensity. We also expected that the cardiovascular threat response (lower CO and higher TPR) would predict less enthusiastic feedback (Peters, Reis, \& Jamieson, 2018a, b).

\section{Method}

\subsection{Participants}

This study involved 224 individuals $(50.00 \%$ female) between the ages of 18 and 33 $(M=22.35, S D=2.62)$ that were in a committed romantic heterosexual relationship for at last two months (Gable et al., 2012). Relationship length ranged from two months to 10 years $(M=2.90$ years, $S D=2.05)$. Approximately $46 \%$ of the sample was in a relationship without living together, $33 \%$ lived together, $15 \%$ was engaged, and $6 \%$ was married. Both dating partners from each couple were tested at the same time in separate cubicles. Of note, we invited couples but tested them as individuals with the same role of the responder in the experiment. We aimed that the participants were not aware of what their partner was actually doing by the physical separation of each person. After their physical separation, participants received specific instructions regarding their role in the experiment (responder) and bogus information about their partner's role (capitalizer). In fact, messages that were supposed to be sent by the capitalizer were predefined messages sent by the computer simulating the capitalizer. Thus, each person in the couple generated the same type of data, i.e., three responses to capitalization attempts. The total number of cases for the analysis was $N=672$. We assumed, however, that the data provided by each participant within a couple were interrelated as a result of emotion coregulation within couples that might occur before the experiment (Butler, 2017) and sharing traits related to emotional processing that might cause the participants to respond in a similar way to stimuli used in our experiment (Watson et al., 2004). Consequently, we accounted for this dependency while running power analysis by using methods recommended for dyadic data (APIMPowerR; Ackerman et al., 2016). We found that at least 92 dyads were needed to achieve sufficient power of 0.80 to detect small-to-medium effect sizes $(\beta=0.20)$ observed in laboratory studies on capitalization (Kashdan et al., 2013). We collected additional data to account for missing data that usually occurs in psychophysiological studies. 
Participants BMI scores ranged between 16.51 and $29.96 \mathrm{~kg} / \mathrm{m}^{2}(M=22.33, S D=2.63)$. Exclusion criteria included a diagnosis of cardiovascular disease or hypertension and BMI > 30. Participants avoided eating for at least one hour before the experiment. They refrained from physical exercise and the intake of caffeine, nicotine, alcohol, or non-prescription drugs for at least two hours before the experiment. Each participant provided written informed consent and received a cinema ticket. Institutional Ethics Committee approved the study.

\subsection{Materials}

\subsubsection{Responses to Capitalization Attempts}

After each success information received from the partner, participants provided verbal/ written (text) and non-verbal (selfie) feedback. This feedback was supposed to be sent to partners, but in fact, it was collected by the computer (Conoley et al., 2015; Kashdan et al., 2013). Accounting for selfies, we aimed to extend the scope of capitalization research by introducing non-verbal social signaling of emotions in responders.

Selfies. We asked participants to send a selfie (i.e., a photograph of themselves) to their partners. Participants looked at the camera located over the PC monitor and pressed Space to have a digital picture taken. Sending selfies, e.g., via social media, is a modern method of communicating emotions (Manovich et al., 2017). Selfies that individuals send to others or distribute via social media usually present posed expressions of emotion that might differ from the spontaneous expressions in their weaker relationship to experience and stronger to socializing intentions (Crivelli et al., 2015).

Verbal RCA. Responders sent the selfie along with a predefined message, which they selected from a range of five choices: (1) enthusiasm for the success (e.g., "Wonderful! You did a great job!"), (2) understated response (e.g., "Ok. Good."), (3) ignoring the success (e.g., "Not much happening here"), (4) demeaning the success (e.g., "I bet the task wasn't very hard"), or (5) refraining from communication and sending no message. Participants were choosing from a new set of predefined responses in each round. This type of responses has been shown to be valid in prior studies as indicated by more positive facial expressions, verbal responses, emotions, and subjective evaluations when the receiver received enthusiastic feedback (Lambert et al., 2013; Monfort et al., 2014; Reis et al., 2010). Responses to capitalization attempts were binary-coded into enthusiastic vs. nonenthusiastic responses based on theoretical considerations (Gable \& Reis, 2010), confirmatory factor analysis (Pagani et al., 2013), as well as research showing the independence and opposition between enthusiastic and non-enthusiastic responses (Demir \& Davidson, 2013; Gable et al., 2004, 2006).

\subsubsection{Elicited Emotions}

In a counterbalanced order, we presented 2-min stimuli from validated film clip databases (Rottenberg et al., 2007; Schaefer et al., 2010). Clips were grouped into three categories: amusement ("The visitors", "When Harry met Sally", "A fish called Wanda"), anger ("American History X","In the name of the father ", "Man bites dog"), and neutral ("Blue", "The lover", "Emperor"). The results section presents the manipulation checks. Data from the validation study indicates that the amusing clips elicit more tenderness, joy, elation, satisfaction, and calmness relative to neutral clips, all Cohen's $d$ s from 0.52 to 3.05; 
medium-to-very large effect sizes (Schaefer et al., 2010). Clips that elicit anger and fear also elicited more disgust, anxiety, shame, sadness, and guilt relative to the neutral clip, all Cohen's $d$ s from 0.49 to 3.39 ; medium-to-very large effect sizes. This suggests that the positive clips elicited amusement along with a wide range of other positive emotions, and negative clips elicited anger along with other negative emotions.

\subsubsection{Emotional Valence}

Participants reported the valence of their emotional experience continuously with Response Meter (ADInstruments, New Zealand) using a slide control with a scale from 1 ("extremely negative") to 10 ("extremely positive"). The signal was sampled at a rate of $1000 \mathrm{~Hz}$ by Powerlab 16/35 (ADInstruments, New Zealand) and further processed using LabChart 8.19 software (ADInstruments, New Zealand). Electronic rating scales are reliable and valid (Ruef \& Levenson, 2007).

\subsubsection{Smiling}

We used an automated facial expression analysis with Quantum Sense (Quantum CX, Poland) validated in prior research (e.g., Kaczmarek et al., 2019) to measure smiling intensity during watching the clips and displayed in selfies. We continuously recorded each participant's facial expressions using an HD camera mounted on the PC screen's top. This software uses a neural network to detect and classify facial expressions by comparing the target face against the prototypical expression of basic emotions. This software returns the intensity of the basic emotions as the percentage of given emotions on a scale from 0 to 1 at each video frame, with higher values representing stronger expressions. We used the percentage of expressions labeled "happiness" as the indicator of smiling intensity. We subtracted baseline smiling intensity from the smiling intensity in response to a stimulus (e.g., watching an amusing clip) to control for individual differences in baseline expressions. Computerized solutions achieve accuracy comparable to naïve human coders for spontaneous facial expressions, higher than naïve human coders for staged facial expressions (Krumhuber et al., 2019), and slightly lower accuracy than FACS coding by trained raters (Lewinski et al., 2014). This system's limitation is that the smiling intensity was evaluated in relation to the prototypical expression of other individuals in the training set that was used for machine learning rather than the participants' own resting and smiling. Moreover, the system did not distinguish between different types of smiles (e.g., Duchenne smiles vs. non-Duchenne smiles). Thus it informed about smiling intensity but not its specific social function (Rychlowska et al., 2017).

\subsubsection{Physiology}

Heart Rate. $\mathrm{Ag}-\mathrm{AgCl}$ surface electrodes placed on the chest were used to record electrocardiogram sampled at $1000 \mathrm{~Hz}$ with BioAmp and Powerlab 16/35 AD converter (ADInstruments, New Zealand). Heart rate in beats per minute (BPM) was calculated with LabChart 8.1 based on the RR intervals in consecutive cardiac cycles. Higher HR reflects sympathetic activation and or parasympathetic withdrawal (Blascovich et al., 2011).

Hemodynamic Parameters. Systolic blood pressure (SBP), diastolic blood pressure (DBP), cardiac output (CO), and total peripheral resistance (TPR) were recorded continuously using Finometer MIDI (Finapres Medical Systems, Netherlands) and Finometer 
NOVA (Finapres Medical Systems, Netherlands) analyzed with BeatScope 2.0 (Finapres Medical Systems, Netherlands). CO (the amount of blood ejected from the heart during a minute) and TPR (a measure of the total vascular resistance) have been used as markers used for the evaluation of threat. Decreases in CO worsen cardiac efficiency and are often observed when individuals are threatened (Jamieson et al., 2012).

Skin Conductance. Electric skin conductance levels were sampled with the GSR Amp (ADInstruments, New Zealand) at $1000 \mathrm{~Hz}$ and reported in microsiemens ( $\mu \mathrm{S}$ ). Electrodes of $8 \mathrm{~mm}$ diameter with a TD-246 sodium chloride paste were attached to the medial phalanges of digits II and IV of the left hand. Skin conductance is a measure of sympathetic arousal and is related to affective processing (Waugh et al., 2011).

\subsection{Procedure}

Upon arrival, couples were separated into cubicles with no eye contact or talking in a sound-attenuated and air-conditioned room. We attached biosensors, instructed participants on using the rating scale for emotion assessments, and informed participants about a cognitive task that one partner would complete while the second partner waited. The experiment began with a 5-min baseline (Fig. 1).

To examine the role of emotions in capitalization responding, we used a validated procedure where each participant was assigned the role of responder and was misinformed that their partner was solving tasks that required high cognitive skills and fast responding (Monfort et al., 2014). In fact, there were no tasks to be actually solved by any of the participants. During the experiment, each participant completed three rounds consisting of (1) waiting for the partner while watching the film clips (T1); (2) receiving bogus information about the partner's success; and (3) sending the feedback (T2). Couples were randomly assigned to three experimental groups, positive emotions elicitation $(n=78)$, negative emotions elicitation $(n=78)$, or a neutral condition $(n=68)$. To elicit emotions, we used 2-min film clips from validated databases (Rottenberg et al., 2007; Schaefer et al., 2010) and presented them in a counterbalanced order.

In each of three rounds, participants were informed by their partner that he or she succeeded in solving the task and was rewarded $\$ 1.50$. This message was, in fact, predefined and sent by the computer. After receiving bogus information about the partner's success, participants provided non-verbal (a selfie) and verbal/written (text response) feedback to partners (Conoley et al., 2015; Kashdan et al., 2013). Finally, participants were screened for suspicion and debriefed. We asked participants whether they were convinced during the

Study Procedure

$\times 3$

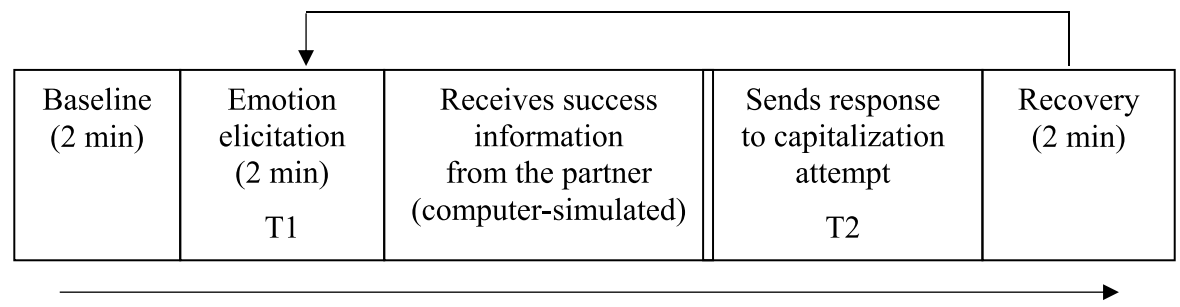

Fig. 1 Study procedure 
experiment that they interacted with their partners on a scale from 1 "completely disagree" to 7 "complete agree"). This indicated credibility of the procedure $(M=5.30, S D=1.70)$. We retained participants who disbelieved the procedure $(n=8,3.6 \%)$ to minimize the risk of between-group bias due to changing the sample composition after randomization (Fisher et al., 2017). Thus, some individuals might have treated the participation as a test of their reaction to an arranged experimental situation.

\subsection{Analytic Strategy}

\subsubsection{Physiological Data Reduction}

To operationalize physiological and affective reactivity, we used reactivity scores corrected for the baseline levels. We subtracted the levels of the last $120 \mathrm{~s}$ of baseline from the level of the $120 \mathrm{~s}$ of responses to partner's feedback. Using difference scores is a standard strategy for studying autonomic responses to emotions (Behnke et al., 2020; Kaczmarek et al., 2019) and capitalization attempts (Monfort et al., 2014; Peters, Reis, \& Jamieson, 2018a, 2018b).

\subsubsection{Manipulation Checks}

First, to examine differences between the conditions on subjective experience, physiological responses, and smiling intensity during baseline, we run a series of analyses of variance (ANOVAs) and calculated effect sizes $\left(\eta^{2}\right)$. To examine differences between the conditions, we calculated pairwise comparisons reported as effect sizes (Cohen's $d$ ) with confidence intervals $(95 \% \mathrm{CI})$. The difference between the two groups is significant when $95 \%$ CI for the effect sizes does not include zero.

Second, to test whether emotional manipulation using film clips influenced subjective experience, physiological responses, and smiling intensity, we regressed responses while watching the film clips on the group the participant belonged to (i.e., positive, negative, and neutral) and sex. Each participant watched three film clips designed to elicit the same emotion providing a nested cluster of three within-person responses. We accounted for dependency between observations by nesting the responses within-person (level 2) and within romantic couples (level 3). The effects of positive or negative emotion elicitation (compared to neutral condition) and sex were considered as significant if the 95\% confidence intervals of regression coefficients did not include zero. We included physiological measures sensitive to the experimental manipulation as potential mediators.

\subsubsection{The Effects of Emotions on Enthusiastic Responding}

We used path analysis to examine the effects of emotions on capitalization attempts using mPlus 8.0 (Muthén \& Muthen, 2017). We run the three-level path analytical model to account for dependency within-person (level 2) and within romantic couples (level 3). We accounted for dependency within couples because each couple might approach the experiment in a similar affective state due to emotion coregulation (Butler, 2017) and because romantic couples share traits that influence emotional processing, such as neuroticism or negative affectivity (Watson et al., 2004). We found dependency within couples for emotional valence, $r=0.25, p<0.001$, and smiling intensity, $r=0.20, p=0.001$. In the mediation model, we regressed the binary outcome (enthusiastic vs. non-enthusiastic feedback) 
(Gable \& Reis, 2010; Gable et al., 2004; Pagani et al., 2013) on the mediators (emotional valence, physiological responses, and smiling intensity while taking a selfie and while watching the film clips), dummy-coded experimental factors (positive, negative, or neutral), and sex. We modeled the relationship between verbal (text) and non-verbal (selfie) responses after the natural process of sending selfies in which individuals usually take their photo first and write text later. Based on models of emotions, we regressed emotion expression on experience and physiological responses while watching the clips (Gross, 2015). We used the binary outcome to reflect whether the verbal feedback given by responders was enthusiastic or non-enthusiastic. Bayesian correction estimator (Bayes) was used to evaluate the path analytical three-level model fit with binary outcomes (Muthén, 2010). Including mediators increases power relative to testing direct effects only (Kenny \& Judd, 2014; O'Rourke \& MacKinnon, 2015). Thus, testing mediations often produces significant mediational paths despite non-significant direct paths when less pronounced effects are studied. We used the Bayesian Posterior Predictive $p(P P p)$ value to evaluate model fit. A well-fitting model should have a $P P p$ value around 0.50 combined with symmetric $95 \%$ credibility intervals centering on zero (Muthén, 2010; Van de Schoot et al., 2014). Data and scripts are available upon request.

\section{Results}

\subsection{Manipulation Checks}

The analysis of variance indicated that there were no differences between groups in baseline levels of tested variables, all $F_{\mathrm{s}}<2.85$, all $p \mathrm{~s}>0.05$ (supplementary materials, Table S1). Individuals who watched the positive film clips reported more positive experiences, $\beta=0.12,95 \%$ CI $[0.04,0.20]$, with more intense smiles, $\beta=0.39,95 \%$ CI $[0.31$, $0.46]$ (Table 1). Negative clips produced more negative experience, $\beta=-0.32,95 \% \mathrm{CI}$ $[-0.40,-0.24]$. The positive film clips produced increases in SBP, $\beta=0.16,95 \%$ CI [0.06, $0.25]$, and DBP, $\beta=0.13,95 \%$ CI [0.03, 0.22], compared to the neutral condition. Negative film clips also produced increases in SBP, $\beta=0.20,95 \%$ CI [0.10, 0.29] and DBP, $\beta=0.16$, $95 \%$ CI $[0.06,0.24]$, compared to the neutral condition. Increased systolic blood pressure and diastolic blood pressure have been previously found for particular negative emotions, such as anger and fear, as well as positive emotions such as happiness and amusement (Kreibig, 2010). In conclusion, we found that the film clips produced meaningful emotional responses between groups as indicated by valence, the intensity of smiling, and physiological responses.

\subsection{The Effects of Emotions on Enthusiastic Responding}

Descriptive statistics are presented in Table 1, and correlations are presented in Table 2. After eliminating participants with missing data, we analyzed 639 responses to capitalization attempts, of which 438 (69\%) were active-constructive or enthusiastic. The significant paths of the mediational model of active-constructive responding are presented in Fig. 2. The model fit the data well, $P P p=0.52,95 \%$ CI $[-25.41,27.88]$ (for correlations matrix, see Table 2). The model also fit the data after excluding participants who disbelieved the procedure, $P P p=0.57,95 \% \mathrm{CI}[-34.46,28.05]$. 


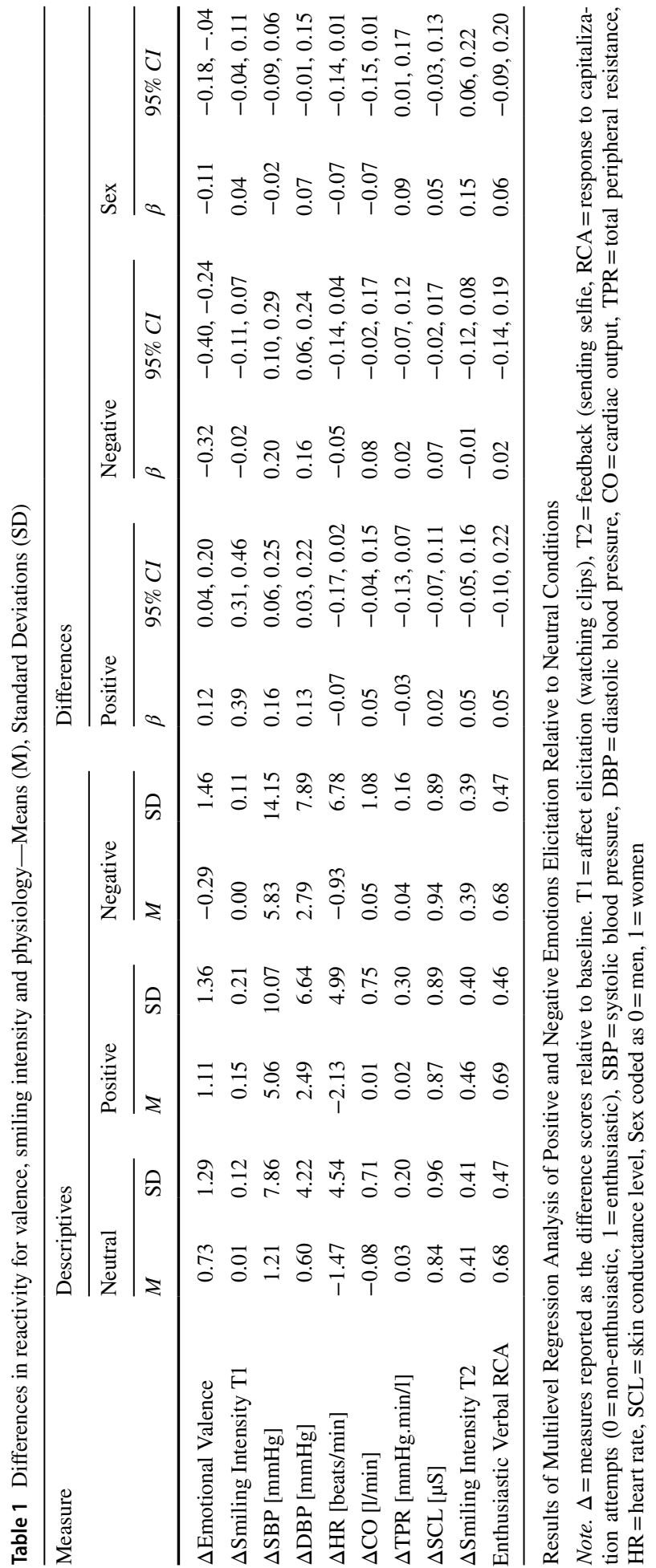


Table 2 Correlations among Study Variables

\begin{tabular}{llllllll}
\hline & & 1 & 2 & 3 & 4 & 5 & 6 \\
\hline 1 & $\Delta$ Emotional Valence T1 & & & & & \\
2 & $\Delta$ Smiling Intensity T1 & $0.23^{* *}$ & & & & \\
3 & $\Delta$ SBP T1 & -0.05 & -0.02 & & & & \\
4 & $\Delta$ DBP T1 & -0.02 & 0.01 & $0.86^{* *}$ & & & \\
5 & $\Delta$ Smiling Intensity T2 & 0.00 & $0.19^{* *}$ & $-0.10^{*}$ & -0.05 & & \\
6 & Enthusiastic Verbal RCA & 0.05 & 0.03 & -0.03 & -0.03 & $0.17 * *$ & \\
7 & Negative Emotions Elicitation & $-0.38^{* *}$ & $-0.22^{* *}$ & $0.12^{* *}$ & $0.09 *$ & -0.05 & 0.00 \\
8 & Positive Emotions Elicitation & $0.29^{* *}$ & $0.40^{* *}$ & 0.05 & 0.05 & 0.08 & 0.01 \\
9 & Sex & $-0.11^{* *}$ & 0.03 & -0.02 & 0.07 & $0.13 * *$ & 0.04 \\
& $M$ & 0.51 & 0.06 & 4.18 & 2.01 & 0.43 & 0.68 \\
& $S D$ & 1.49 & 0.17 & 11.49 & 6.68 & 0.40 & 0.47 \\
\hline
\end{tabular}

$* p<.05, * * p<.01$

Note. $\Delta=$ measures reported as the difference scores relative to baseline. Coding: $\operatorname{sex}(0=$ men, $1=$ women $)$, $\mathrm{T} 1=$ affect elicitation (watching clips), $\mathrm{T} 2=$ feedback (selfie), $\mathrm{SBP}=$ systolic blood pressure, $\mathrm{DBP}=\mathrm{dias}-$ tolic blood pressure, RCA = response to capitalization attempts $(0=$ non-enthusiastic, $1=$ enthusiastic $)$, Group $\mathrm{P}=$ positive emotions elicitation (dummy coded $0=$ no, $1=$ yes), Group $\mathrm{N}=$ negative emotions elicitation (dummy coded $0=$ no, $1=$ yes)

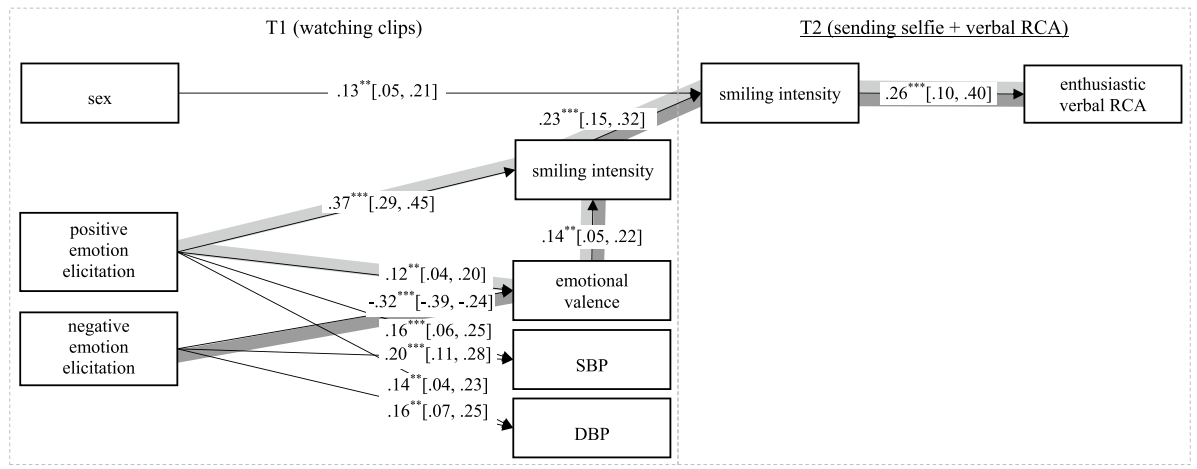

Fig. 2 Affective model for enthusiastic responses to capitalization attempts

Path analysis revealed that individuals who sent selfies with more intense smiles to partners and were more likely to send enthusiastic verbal RCA (Fig. 2). Moreover, we found two significant indirect effects of positive emotions elicitation on sending enthusiastic verbal RCA. First, indirect effects operated via the intensity of smiling when watching the positive film clips and via the intensity of smiling on selfies, $\beta=0.015,95 \% \mathrm{CI}$ $[0.004,0.030]$. Second, individuals that experienced more positive emotions (emotion valence) when watching positive film clips smiled more intensely while watching the film clips, smiled more intensely on selfies, and in turn send enthusiastic feedback more often $\beta=0.001,95 \%$ CI $[0.0001,0.002]$. We also observed an opposite indirect effect for negative emotions, namely individuals that experienced more negative emotions when watching the negative film clips, smiled less intense while watching the film clips, smiled less intense on their selfies, and, in turn, sent enthusiastic feedback less often, $\beta=-0.002,95 \%$ 
CI $[-0.004,-0.0001]$. The indirect effect for negative emotion elicitation on enthusiastic verbal RCA via smiling intensity when watching the negative clips and smiling intensity on selfies was not significant, $\beta=0.003,95 \%$ CI $[-0.010,0.018]$. Physiological responses were not predictive of verbal or non-verbal communication during capitalization attempts, all $p s>0.05$. Women sent happier selfies to partners compared to men.

\section{Discussion}

This study tested whether responses to partner's capitalization attempts depend on elicited positive and negative emotions. We found that smiling intensity predicted more enthusiastic responses to capitalization attempts. Furthermore, elicited positive emotions (marked by more pleasant emotions and more intense smiles) translated into more positive verbal and non-verbal communication following their partner's capitalization attempts. Together, the results suggest that responding to capitalization attempts depends on the partner's emotional states, with partners experiencing more intense positive emotions being more likely to respond more enthusiastically. Our findings lend support to the emotion-as-direct-causation (versus emotion-as-feedback) hypothesis regarding social behavior (DeWall et al., 2016) as well as the broaden-and-build model of positive emotions (Fredrickson, 2001).

We found that sharing success with a person experiencing mild negative emotions caused a disadvantage compared to neutral conditions. This supports prior work suggesting that intense and prolonged negative emotions inhibit healthy capitalization attempts and support (Otto et al., 2015). We presented that brief negative emotional episodes, such as those observed in our study, also threaten capitalization support quality. As we found that emotion-eliciting situations influenced responses to capitalization attempts, future studies might reveal other contextual factors that generate enthusiastic responses and, in turn, increase the occurrence of capitalization attempts (e.g., Kaczmarek et al., 2021).

We also found evidence of the critical role of smiling intensity. There is increasing evidence for positive expressive behavior as part of understanding and altering capitalization outcomes. It will be useful to uncover how this effect operates in life domains such as schools, workplaces, and competitions. If the results replicate, practical implications exist for social skill and leadership development.

We found no evidence for the mediating role of physiological reactivity in influencing capitalization outcomes. While elicited emotions increased physiological mobilization (SBP and DBP), these changes did not mediate how individuals responded to capitalization attempts as partners. This corresponds with a similar study where effects for facial expression but not for physiological responses were observed (Monfort et al., 2014). However, another study found that more intense cardiovascular threat responses correlated with less enthusiastic responses to capitalization attempts (Peters, Reis, \& Jamieson, 2018a, 2018b).

We found significant indirect effects of elicited emotions on RCA but the direct effects of elicited emotions on RCA were non-significant. Such indirect effects are likely to exist in model testing due to higher statistical power when testing indirect effects relative to testing direct effects (Kenny \& Judd, 2014; O'Rourke \& MacKinnon, 2015). Indirect effects are products of two or more paths. Therefore they have more statistical power than single coefficients that represent direct effects. This might be the case for the present study, where the effects of emotions were relatively small with standardized betas ranging from 0.12 to 0.37 . Our results indicate the advantage of the mediational analytical plan. They suggest 
that even greater statistical power would be required to ascertain that the effects of emotions on RCA are likely to replicate in studies that use different or no mediators.

We found sex differences to be relevant to capitalization. Women submitted selfies with more intense smiles to their partners than men and selected more enthusiastic feedback in response to their partner's accomplishments. This adds to a body of work suggesting women show greater prosocial tendencies than men (e.g., Dindia \& Allen, 1992; Taylor, 2006). In this case, these tendencies are fueled by greater positive emotional expressiveness.

These findings have practical implications. The effects observed indicate that elicited positive emotions might help individuals in building enthusiastic responses. Individuals might use external sources of positive emotions (e.g., desirable food, entertainment, and serene settings) to boost capitalization support skills temporarily. Moreover, individuals might resist producing capitalization attempts until their partner expresses positive emotions. Smiling intensity might be indicative of the readiness of partners to engage in enthusiastic support. Someone might intentionally boost their partner's mood (e.g., playfulness) before the capitalization attempt to receive stronger capitalization support.

\subsection{Limitations and Future Directions}

This study has several limitations. First, the effects that we observed were small and indirect. Applied studies might test whether the effects produced in our study have substantial practical meaning. Second, we provided evidence for specific clips' effects, but we cannot pinpoint which and whether some specific positive or negative emotions were producing the observed effects. This is because each group of clips that we used (positive and negative) targeted one specific emotion (e.g., amusement) but also elicited substantial intensity of other positive emotions (e.g., tenderness) (Schaefer et al., 2010). Thus, it is difficult to ascertain whether the targeted emotion produced specific effects or any other accompanying emotion or interaction of both. Moreover, different findings might emerge from comparisons between affective states dominated by other positive (e.g., tenderness, pride) and negative (e.g., sadness, shame) emotions. This indicates that the range of conclusions regarding specific stimuli and specific emotions should be interpreted with caution. Further studies might examine whether some positive emotions, e.g., relational positive emotions such as tenderness, are more efficient in influencing enthusiastic feedback towards partner's success than others, e.g., joy.

Third, the results might have been different for longer romantic relationships and older adults. Self-selected couples participated in these studies and might not be representative of typical romantic couples. Fourth, individuals communicated using a predefined set of messages rather than writing them on their own (Monfort et al., 2014). The results might differ if participants generated messages on their own because of the requirement to (1) be enthusiastic for partners and (2) possess sufficient knowledge and skill in constructing a persuasive, enthusiastic RCA. Fifth, the participants in our study were mostly young adults. Thus, the generalizability of findings does not extend across the age span. Sixth, we accounted for smiling intensity but not for qualitative differences between smiles that reflect smiling social functions (Rychlewska et al., 2017). We were also not able to distinguish between Duchenne and non-Duchenne smiles. It is important to note that the Duchenne smile is interpreted as a marker of genuine happiness or enjoyment (Ekman et al., 1990; Frank et al., 1993). We also did not account for gestures that might further enhance emotion expression assessment accuracy (Sun et al., 2018). Seventh, due to our focus on 
interpersonal communication, we analyzed selfies that present posed expressions of emotion that differ from the spontaneous expressions of emotion (Krumhuber et al., 2019) and are loosely related to experience (Crivelli et al., 2015).

Finally, although the hypothesized model fit the data well, the order of the model elements might be organized differently as elements in $\mathrm{T} 1$ and $\mathrm{T} 2$ covered responses to the same stimulus, i.e., a film clip and the partner's capitalization attempt, respectively. Finally, the effects of clips on positive and negative affect that we observed were smaller than the average effects found in other studies (Joseph et al., 2020). Responders might have been emotionally engaged in the social interaction waiting for their partner's results. Mixed emotions were likely to occur in some participants, e.g., anxiety related to the partner's performance and amusement related to watching the clip. The effects of clips might be stronger if responders were not aware that their partner was struggling with a difficult task and the capitalization attempt arrived as a surprise.

\subsection{Conclusion}

We indicated that responses to capitalization attempts are malleable via mild emotional influences. Our findings add knowledge about under what conditions capitalization attempts are more likely to produce active-constructive feedback (Peters, Reis, \& Gable, 2018a, 2018b). This work adds to a cumulative science on positive emotions as a robust, reliable method for inducing and maintaining healthier and stronger social relationships.

Supplementary Information The online version contains supplementary material available at https://doi. org/10.1007/s10902-021-00389-y.

Authors' Contributions LDK, TBK, and PG contributed to the study conception and design. Material preparation and analysis were performed by MB, LDK, and PG. Data was collected by MB, MD, EM, MK, and JE. The first draft of the manuscript was written by LDK, TBK, and MB, and all authors commented on the manuscript. All authors read and approved the final manuscript.

Funding This project was funded by the National Science Centre, Poland (UMO-2014/15/B/HS6/02418) awarded to LDK (principal investigator), TBK (key investigator), and PG (key investigator). Preparation of this article was supported by doctoral scholarships from National Science Centre in Poland (UMO2019/32/T/HS6/00039) and Adam Mickiewicz University Foundation to MB.

Availability of data and material In regard to data privacy policy at the Adam Mickiewicz University we cannot make full data publicly available, but we will share all materials and required data in a timely manner to other researchers upon request.

\section{Declatarions}

Conflict of interest The authors declare no conflict of interest.

Consent to participate Each participant provided written informed consent.

Consent for publication All authors whose names appear on the submission 1) made substantial contributions to the conception or design of the work; or the acquisition, analysis, or interpretation of data; or the creation of new software used in the work; 2) drafted the work or revised it critically for important intellectual content; 3) approved the version to be published; and 4) agree to be accountable for all aspects of the work in ensuring that questions related to the accuracy or integrity of any part of the work are appropriately investigated and resolved.

Ethical Approval Institutional Ethics Committee of Faculty of Psychology and Cognitive Science Adam Mickiewicz University approved the study. 
Open Access This article is licensed under a Creative Commons Attribution 4.0 International License, which permits use, sharing, adaptation, distribution and reproduction in any medium or format, as long as you give appropriate credit to the original author(s) and the source, provide a link to the Creative Commons licence, and indicate if changes were made. The images or other third party material in this article are included in the article's Creative Commons licence, unless indicated otherwise in a credit line to the material. If material is not included in the article's Creative Commons licence and your intended use is not permitted by statutory regulation or exceeds the permitted use, you will need to obtain permission directly from the copyright holder. To view a copy of this licence, visit http://creativecommons.org/licenses/by/4.0/.

\section{References}

Ackerman, R. A., Ledermann, T., \& Kenny, D. A. (2016). Power analysis for the actor-partner interdependence model. Unpublished manuscript. Retrieved from https://robert-ackerman.shinyapps.io/APIMP owerR

Aknin, L. B., Ven de Vondervoort, J. W., \& Hamlin, J. K. (2017). Positive feelings reward and promote prosocial behaviour. Current Opinion in Psychology, 20, 55-59. https://doi.org/10.1016/j.copsyc.2017. 08.017.

Behnke, M., Gross, J. J., \& Kaczmarek, L. D. (2020). The role of emotions in esports performance. Emotion, Advanced Online Publication. https://doi.org/10.1037/emo0000903.

Behnke, M., \& Kaczmarek, L. D. (2018). Successful performance and cardiovascular markers of challenge and threat: A meta-analysis. International Journal of Psychophysiology, 130, 73-79. https://doi.org/10. 1016/j.ijpsycho.2018.04.007.

Butler, E. A. (2017). Emotions are temporal interpersonal systems. Current Opinion in Psychology, 17, 129-134. https://doi.org/10.1016/j.copsyc.2017.07.005.

Blascovich, J., Vanman, E. J., Mendes, W. B., \& Dickerson, S. (2011). The SAGE library of methods in social and personality psychology.Social psychophysiology for social and personality psychology. Sage Publications Ltd.

Cacioppo, J. T., \& Berntson, G. G. (1994). Relationship between attitudes and evaluative space: A critical review, with emphasis on the separability of positive and negative substrates. Psychological Bulletin, 115, 401-423. https://doi.org/10.1037/0033-2909.115.3.401.

Crivelli, C., Carrera, P., \& Fernández-Dols, J. M. (2015). Are smiles a sign of happiness? Spontaneous expressions of judo winners. Evolution and Human Behavior, 36(1), 52-58. https://doi.org/10.1016/j. evolhumbehav.2014.08.009.

Crivelli, C., \& Fridlund, A. J. (2018). Facial displays are tools for social influence. Trends in Cognitive Sciences, 22(5), 388-399. https://doi.org/10.1016/j.tics.2018.02.006.

Conoley, C. W., Vasquez, E., Bello, B. D. C., Oromendia, M. F., \& Jeske, D. R. (2015). Celebrating the accomplishments of others: Mutual benefits of capitalization. The Counseling Psychologist. 43, 734751. https://doi.org/10.1177\%2F0011000015584066

Demir, M., \& Davidson, I. (2013). Toward a better understanding of the relationship between friendship and happiness: Perceived responses to capitalization attempts, feelings of mattering, and satisfaction of basic psychological needs in same-sex best friendships as predictors of happiness. Journal of Happiness Studies, 14, 525-550. https://doi.org/10.1007/s10902-012-9341-7.

DeWall, C. N., Baumeister, R. F., Chester, D. S., \& Bushman, B. J. (2016). How often does currently felt emotion predict social behavior and judgment? A meta-analytic test of two theories. Emotion Review, 8, 136-143. https://doi.org/10.1177/1754073915572690.

Dindia, K., \& Allen, M. (1992). Sex differences in self-disclosure: A meta-analysis. Psychological Bulletin, 112, 106-124. https://doi.org/10.1037/0033-2909.112.1.106.

Donato, S., Pagani, A., Parise, M., Bertoni, A., \& Iafrate, R. (2014). The capitalization process in stable couple relationships: Intrapersonal and interpersonal benefits. Procedia-Social and Behavioral Sciences, 140, 207-211. https://doi.org/10.1016\%2Fj.sbspro.2014.04.411

Drążkowski, D., Kaczmarek, L. D., \& Kashdan, T. B. (2017). Gratitude pays: A weekly gratitude intervention influences monetary decisions, physiological responses, and emotional experiences during a trustrelated social interaction. Personality and Individual Differences, 110, 148-153.

Ekman, P., Davidson, R. J., \& Friesen, W. V. (1990). The Duchenne smile: Emotional expression and brain physiology: II. Journal of Personality and Social Psychology, 58(2), 342-353. https://doi.org/10.1037/ 0022-3514.58.2.342.

Enko, J., Behnke, M., Dziekan, M., Kosakowski, M., \& Kaczmarek, L. D. (2020). Gratitude Texting Touches the Heart: Challenge/Threat Cardiovascular Responses to Gratitude Expression Predict 
Self-initiation of Gratitude Interventions in Daily Life. Journal of Happiness Studies, 1-21,. https:// doi.org/10.1007/s10902-020-00218-8.

Fisher, L. D., Dixon, D. O., Herson, J., Frankowski, R. F., Hearron, M. S., \& Peace, K. E. (2017). Intention to treat in clinical trials. In: Statistical Issues in Drug Research and Development (pp. 331-350). CRC Press. https://doi.org/10.1201/9780203738610

Frank, M. G., Ekman, P., \& Friesen, W. V. (1993). Behavioral markers and recognizability of the smile of enjoyment. Journal of Personality and Social Psychology, 64(1), 83-93. https://doi.org/10.1037/00223514.64.1.83.

Fredrickson, B. L. (2001). The role of positive emotions in positive psychology: The broaden-and-build theory of positive emotions. American Psychologist, 56, 218-229. https://doi.org/10.1037/0003066X.56.3.218.

Fredrickson, B. L., Cohn, M. A., Coffey, K. A., Pek, J., \& Finkel, S. M. (2008). Open hearts build lives: positive emotions, induced through loving-kindness meditation, build consequential personal resources. Journal of Personality and Social Psychology, 95, 1045-1056. https://doi.org/10.1037/ $\mathrm{a} 0013262$.

Frijda, N. H. (1986). The emotions. Cambridge University Press.

Gable, S. L., Gonzaga, G. C., \& Strachman, A. (2006). Will you be there for me when things go right? Supportive responses to positive event disclosures. Journal of personality and social psychology, 91, 904-917. https://doi.org/10.1037/0022-3514.91.5.904.

Gable, S. L., Gosnell, C. L., Maisel, N. C., \& Strachman, A. (2012). Safely testing the alarm: Close others' responses to personal positive events. Journal of Personality and Social Psychology, 103, 963-981. https://doi.org/10.1037/a0029488.

Gable, S. L., \& Reis, H. T. (2010). Good news! Capitalizing on positive events in an interpersonal context. In M. P. Zanna (Ed.), Advances in experimental social psychology. Advances in experimental social psychology, Vol. 42 (p. 195-257). https://doi.org/10.1016/S0065-2601(10)42004-3

Gable, S. L., Reis, H. T., Impett, E. A., \& Asher, E. R. (2004). What Do You Do When Things Go Right? The Intrapersonal and Interpersonal Benefits of Sharing Positive Events. Journal of Personality and Social Psychology, 87, 228-245. https://doi.org/10.1037/0022-3514.87.2.228.

Gouin, J. P., Caldwell, W. C., MacNeil, S. L., \& Roddick, C. M. (2019). Respiratory sinus arrhythmia reactivity moderates within-person associations of daily capitalization with positive affect and relationship quality. Journal of Social and Personal Relationships, 36(9), 2896-2917.

Gross, J. J. (2015). Emotion regulation: Current status and future prospects. Psychological Inquiry, 26(1), 1-26. https://doi.org/10.1080/1047840X.2014.940781.

Horn, A. B., Milek, A., Brauner, A., \& Maercker, A. (2017). Less positive sharing in the couple mediates the link between depression and relationship quality: A dyadic longitudinal study. Journal of Social and Clinical Psychology, 36, 535-553. https://doi.org/10.1521/jscp.2017.36.7.535.

Ilies, R., Keeney, J., \& Goh, Z. W. (2015). Capitalising on positive work events by sharing them at home. Applied Psychology, 64, 578-598. https://doi.org/10.1111/apps.12022.

Izard, C. E., \& Ackerman, B. (2000). Motivational, organizational, and regulatory functions of discrete emotions. In M. Lewis \& J. M. Haviland-Jones (Eds.), Handbook of emotions. (2nd ed., pp. 253264). Guilford.

Jamieson, J. P., Nock, M. K., \& Mendes, W. B. (2012). Mind over matter: reappraising arousal improves cardiovascular and cognitive responses to stress. Journal of Experimental Psychology: General, 141, 417-422. https://doi.org/10.1037/a0025719.

Joseph, D. L., Chan, M. Y., Heintzelman, S. J., Tay, L., Diener, E., \& Scotney, V. S. (2020). The manipulation of affect: A meta-analysis of affect induction procedures. Psychological Bulletin, 146, 355375. https://doi.org/10.1037/bul0000224.

Kaczmarek, L. D., Behnke, M., Kosakowski, M., Enko, J., Hughes, B., Piskorski, J., \& Guzik, P. (2019). Effects of emotions on heart rate symmetry. Psychophysiology, 54, 1-12. https://doi.org/10.1111/ psyp. 13318 .

Kaczmarek, L. D., Kelso, K. C., Behnke, M., Kashdan, T. B., Dziekan, M., Matuła, K., Kosakowski, M., Enko, J., \& Guzik, P. (2021). Give and take: The role of reciprocity in capitalization. The Journal of Positive Psychology. https://doi.org/10.1080/17439760.2021.1885054.

Kashdan, T. B., Ferssizidis, P., Farmer, A. S., Adams, L. M., \& McKnight, P. E. (2013). Failure to capitalize on sharing good news with romantic partners: Exploring positivity deficits of socially anxious people with self-reports, partner-reports, and behavioral observations. Behaviour Research and Therapy, 51, 656-668. https://doi.org/10.1016/j.brat.2013.04.006.

Kenny, D. A., \& Judd, C. M. (2014). Power anomalies in testing mediation. Psychological Science, 25, 334-339.https://doi.org/10.1177/0956797613502676. 
Kreibig, S. D. (2010). Autonomic nervous system activity in emotion: a review. Biological Psychology, 84, 394-421. https://doi.org/10.1016/j.biopsycho.2010.03.010.

Krumhuber, E. G., Küster, D., Namba, S., Shah, D., \& Calvo, M. G. (2019). Emotion recognition from posed and spontaneous dynamic expressions: Human observers versus machine analysis. Emotion. https://doi.org/10.1037/emo0000712.

Lambert, N. M., Gwinn, A. M., Baumeister, R. F., Strachman, A., Washburn, I. J., Gable, S. L., et al. (2013). A boost of positive affect: The perks of sharing positive experiences. Journal of Social and Personal Relationships, 30, 24-43. https://doi.org/10.1177/0265407512449400.

Langston, C. A. (1994). Capitalizing on and coping with daily-life events: Expressive responses to positive events. Journal of Personality and Social Psychology, 67, 1112-1125. https://doi.org/10.1037/00223514.67.6.1112.

Lewinski, P., den Uyl, T. M., \& Butler, C. (2014). Automated facial coding: Validation of basic emotions and FACS AUs in FaceReader. Journal of Neuroscience, Psychology, and Economics, 7(4), 227-236. https://doi.org/10.1037/npe0000028.

Manovich, L., Ferrari, V., \& Bruno, N. (2017). Selfie-Takers Prefer Left Cheeks: Converging Evidence from the (Extended) selfiecity Database. Frontiers in Psychology, 8, 1460. https://doi.org/10.3389/fpsyg. 2017.01460.

Mauss, I. B., Levenson, R. W., McCarter, L., Wilhelm, F. H., \& Gross, J. J. (2005). The tie that binds? Coherence among emotion experience, behavior, and physiology. Emotion, 5(2), 175-190. https://doi. org/10.1037/1528-3542.5.2.175.

Mauss, I. B., \& Robinson, M. D. (2009). Measures of emotion: A review. Cognition and Emotion, 23(2), 209-237. https://doi.org/10.1080/02699930802204677.

Monfort, S. S., Kaczmarek, L. D., Kashdan, T. B., Drążkowski, D., Kosakowski, M., Guzik, P., Krauze, T., \& Gracanin, A. (2014). Capitalizing on the success of romantic partners: A laboratory investigation on subjective, facial, and physiological emotional processing. Personality and Individual Differences, 68, 149-153. https://doi.org/10.1016/j.paid.2014.04.028.

Muthén, L. K., \& Muthen, B. (2017). Mplus user's guide: Statistical analysis with latent variables, user's guide. Muthén \& Muthén.

Muthén, B. (2010). Bayesian analysis in Mplus: A brief introduction.

Netzer, L., Van Kleef, G. A., \& Tamir, M. (2015). Interpersonal instrumental emotion regulation. Journal of Experimental Social Psychology, 58, 124-135. https://doi.org/10.1016/j.jesp.2015.01.006.

O'Rourke, H. P., \& MacKinnon, D. P. (2015). When the test of mediation is more powerful than the test of the total effect. Behavior Research Methods, 47, 424-442. https://doi.org/10.3758/s13428-014-0481-z.

Otto, A. K., Laurenceau, J. P., Siegel, S. D., \& Belcher, A. J. (2015). Capitalizing on everyday positive events uniquely predicts daily intimacy and well-being in couples coping with breast cancer. Journal of Family Psychology, 29, 69-79. https://doi.org/10.1037/fam0000042.

Pagani, A. F., Donato, S., \& Iafrate, R. (2013). Actively dealing with good fortune? Confirmatory factor analysis and gender invariance of the Perceived Responses to Capitalization Attempts (PRCA) scale. TPM: Testing. Psychometrics, Methodology in Applied Psychology, 20, 101-116.

Peters, B. J., Reis, H. T., \& Gable, S. L. (2018a). Making the good even better: A review and theoretical model of interpersonal capitalization. Social and Personality Psychology Compass, 12, e12407. https://doi.org/10.1111/spc3.12407.

Peters, B. J., Reis, H. T., \& Jamieson, J. P. (2018b). Cardiovascular indexes of threat impair responsiveness in situations of conflicting interests. International Journal of Psychophysiology, 123, 1-7. https://doi. org/10.1016/j.ijpsycho.2017.12.005.

Reis, H. T., Smith, S. M., Carmichael, C. L., Caprariello, P. A., Tsai, F. F., Rodrigues, A., \& Maniaci, M. R. (2010). Are you happy for me? How sharing positive events with others provides personal and interpersonal benefits. Journal of Personality and Social Psychology, 99, 311-329. https://doi.org/10.1037/ a0018344.

Reis, H. T., Maniaci, M. R., \& Rogge, R. D. (2017). Compassionate acts and everyday emotional well-being among newlyweds. Emotion, 17(4), 751-763. https://doi.org/10.1037/emo0000281.

Rottenberg, J., Ray, R. D., \& Gross, J. J. (2007). Emotion elicitation using films. In J. A. Coan \& J. J. B. Allen (Eds.), The handbook of emotion elicitation and assessment. (pp. 9-28). Oxford University Press.

Ruef, A. M., \& Levenson, R. W. (2007). Continuous measurement of emotion: The affect rating dial. In J. A. Coan \& J. J. B. Allen (Eds.), Series in affective science. Handbook of emotion elicitation and assessment(pp. 286-297). New York, NY, US: Oxford University Press.

Russell, J. A., \& Carroll, J. M. (1999). On the bipolarity of positive and negative affect. Psychological Bulletin, 125, 3-30. https://doi.org/10.1037/0033-2909.125.1.3. 
Rychlowska, M., Jack, R. E., Garrod, O. G., Schyns, P. G., Martin, J. D., \& Niedenthal, P. M. (2017). Functional smiles: Tools for love, sympathy, and war. Psychological Science, 28(9), 1259-1270. $10.1177 \% 2 \mathrm{~F} 0956797617706082$

Schaefer, A., Nils, F., Sanchez, X., \& Philippot, P. (2010). Assessing the effectiveness of a large database of emotion-eliciting films: A new tool for emotion researchers. Cognition \& Emotion, 24, 1153-1172. https://doi.org/10.1080/02699930903274322.

Schueller, S. M. (2012). Personality fit and positive interventions: Extraverted and introverted individuals benefit from different happiness increasing strategies. Psychology, 3, 1166-1173. https://doi.org/10. 4236/psych.2012.312A172.

Seligman, M. E., Ernst, R. M., Gillham, J., Reivich, K., \& Linkins, M. (2009). Positive education: Positive psychology and classroom interventions. Oxford Review of Education, 35, 293-311. https://doi.org/10. 1080/03054980902934563.

Shallcross, S. L., Howland, M., Bemis, J., Simpson, J. A., \& Frazier, P. (2011). Not “capitalizing” on social capitalization interactions: The role of attachment insecurity. Journal of Family Psychology, 25, 77-85. https://doi.org/10.1037/a0021876.

Shiota, M. N., Neufeld, S. L., Yeung, W. H., Moser, S. E., \& Perea, E. F. (2011). Feeling good: autonomic nervous system responding in five positive emotions. Emotion, 11, 1368-1378. https://doi.org/10. $1037 / \mathrm{a} 0024278$.

Sun, B., Cao, S., He, J., \& Yu, L. (2018). Affect recognition from facial movements and body gestures by hierarchical deep spatio-temporal features and fusion strategy. Neural Networks, 105, 36-51. https:// doi.org/10.1016/j.neunet.2017.11.021.

Strack, F., \& Deutsch, R. (2004). Reflective and impulsive determinants of social behavior. Personality and social psychology review, 8(3), 220-247. https://doi.org/10.1207/s15327957pspr0803_1

Taylor, S. E. (2006). Tend and befriend: Biobehavioral bases of affiliation under stress. Current Directions in Psychological Science, 15, 273-277. https://doi.org/10.1111/j.1467-8721.2006.00451.x

Van de Schoot, R., Kaplan, D., Denissen, J., Asendorpf, J. B., Neyer, F. J., \& Van Aken, M. A. (2014). A gentle introduction to Bayesian analysis: Applications to developmental research. Child Development, 85(3), 842-860. https://doi.org/10.1111/cdev.12169.

Watson, D., Klohnen, E. C., Casillas, A., Simms, E. N., \& Haig, J. (2004). Match makers and deal breakers: Analyses of assortativemating in newlywed couples. Journal of Personality, 72, 1029-1069. https:// doi.org/10.1111/j.0022-3506.2004.00289.x.

Waugh, C. E., Thompson, R. J., \& Gotlib, I. H. (2011). Flexible emotional responsiveness in trait resilience. Emotion, 11, 1059-1067. https://doi.org/10.1037/a0021786.

Woods, S., Lambert, N., Brown, P., Fincham, F., \& May, R. (2015). "I'm so excited for you!" How an enthusiastic responding intervention enhances close relationships. Journal of Social and Personal Relationships, 32, 24-40. https://doi.org/10.1177/0265407514523545.

Zaki, J., \& Williams, W. C. (2013). Interpersonal emotion regulation. Emotion, 13(5), 803-810. https://doi. org/10.1037/a003383.

Publisher's Note Springer Nature remains neutral with regard to jurisdictional claims in published maps and institutional affiliations. 